\title{
XLVI. On the remarkable relationships between the spectrum of water-vapour and the line-spectra of hydrogen and oxygen, and on the chemical structure of the two latter, and their dissociation in the sun's atmosphere
}

\section{Prof. A. Grünwald}

To cite this article: Prof. A. Grünwald (1887) XLVI. On the remarkable relationships between the spectrum of water-vapour and the line-spectra of hydrogen and oxygen, and on the chemical structure of the two latter, and their dissociation in the sun's atmosphere, Philosophical Magazine Series 5, 24:149, 354-367, DOI: 10.1080/14786448708628111

To link to this article: http://dx.doi.org/10.1080/14786448708628111

\section{曲 Published online: 29 Apr 2009.}

\section{Submit your article to this journal 둔}

Џll Article views: 2 


\section{$\left[\begin{array}{ll}354 & ]\end{array}\right.$}

XLVI. On the remarkable Relationships between the Spectrum. of Water-vapour and the Line-spectra of Hydrogen and Oxygen, and on the Chemical Structure of the two latter, and their Dissociation in the Sun's Atmosphere. By Prof. A. GRÜNWALO*.

BY means of a mathematical investigation into the changes $B$ which the properties, and in particular the spectra, of two gases undergo upon their chemical combination to form a new substance, I have succeeded in discovering the law, as simple as it is important, of a new mathematico-chemical disturbance-theory ; and by its aid in finding very remarkable relationships between the spectra of hydrogen and oxygen on the one hand, and of water-vapour on the other, as well as discovering the chemically compound nature of hydrogen and oxygen by mathematico-spectral analysis, and in demonstrating the dissociation of hydrogen in the sun's atmosphere.

\section{I.}

The above-mentioned fundamental theorem is as follows:-

"Let $a$ be a primary chemical element, which is chemically combined with other elements in a gaseous substance $\mathrm{A}$, and occupies the volume $[a]$ in the unit-volume of $A$. Let the substance A combine chemically with another gaseous substance, $B$, to form a third, C. In this combination let the element $a$ pass into a different chemical condition, $a^{\prime}$, giving up (or in exceptional cases taking up) a certain quantity of heat in order to permit the new compound to form, and in consequence chemically contracting (or exceptionally expanding). Let the volume which it occupies in the body $\mathrm{C}$, after the new condition of chemical equilibrium has been established, be $\left[a^{\prime}\right]$, when the quotient $[a]:\left[a^{\prime}\right]$ is generally a very simple rational number in accordance with a known fundamental law of chemistry. If this is the case, the wave-lengths $\lambda$ of all the rays which belong to the element $a$ in the line-spectrum of the free substance $A$, and are therefore radiated by it, are related to the wave-lengths $\lambda^{\prime}$ of the corresponding rays which the same element emits in the new chemical condition $a^{\prime}$, in which it exists in the more complex substance $A$ within the newly formed compound $\mathrm{C}$, as the corresponding volumes [a] and $\left[a^{\prime}\right] . "$

This theorem only holds good when the substances in question are gases which are at a considerable distance from the critical point of condensation, and are not under too great

* Communicated by the Author from the Astr. Nachr. Bd.117. 
pressure. The modifications which it requires when these conditions are not fulfilled, as well as the simple and natural assumptions upon which the proof of the theorem rests, can only be given in a fuller communication.

From the above proposition it follows in particular that for $\left[a^{\prime}\right]=[a], i . e$. if the volume of the element $a$ in the new compound $\mathrm{C}$ is the same as in the original substance $\mathrm{A}$, the wave-lengths $\lambda^{\prime}$ of the rays emitted by $a^{\prime}$ must be equal to the wave-lengths $\lambda$ previously produced by $a$. The only difference will consist simply in a varying change in the amplitudes and consequently in the intensities of the individual rays; from which it results that the brightness of a whole series of rays is so much diminished that they cease to be visible, whereas others become brighter. Thus the spectra of the compounds formed by the union of hydrogen with chlorine, bromine, and iodine (viz. $\mathrm{HCl}, \mathrm{HBr}, \mathrm{HI}$ ) consist only of the spectra of hydrogen on the one hand, and of chlorine, bromine, or iodine on the other, but with characteristic changes of intensity of the various rays of their components.

The limitation to the gaseous condition is necessary because, as in chemistry generally so here, easily observable relationships exist only for gases. If the pressure increases, or if the gaseous substances in consequence of falling temperature (or with simultaneous increase of pressure) approach the temperature of liquefaction, the number of impacts between two different molecules will be increased under otherwise similar conditions; and the number of vibrations of the equivalent smallest particles of the different similarly constituted molecules of the same substance are altered in varying fashion by varying impacts. Whilst in the former case equivalent corresponding smallest particles of different similarly constituted molecules of the same substance emit extraordinarily feeble rays of equal wave-length, which in the spectrum are superposed, and by addition of their extremely small intensities produce a single ray of perceptible brightness, in the latter case equivalent particles of different like-constituted molecules emit not only rays of normal period, but also rays of periods more or less different from the normal, which arise from the impacts of different kinds. T'ogether with the normal line, we have close to it rays of the latter kind-that is, the original sharp line becomes widened. If the pressure increases and the gases approach their point of liquefaction, such a line becomes still further widened; and it may bappen that the resulting band-like line may extend as far as lines due to heterogeneous particles of the different molecules of the same substance. The lines of the spectrum run together, and there 
results a more or less continuous spectrum, in which only some light-maxima show the position of the former chief lines of the normal spectrum.

\section{II.}

The most important of the highly remarkable relationships between the line spectra of $\mathrm{H}, \mathrm{O}$, and $\mathrm{H}_{2} \mathrm{O}$ vapour are :-

(1) "All the waves of the second or so-called compoundline spectrum of hydrogen, which have been so admirably determined by Dr. B. Hasselberg, of Pulkowa, and which are due to a more complicated structure of $\mathrm{H}$ molecules, may (after exclusion of the lines belonging to the elementary linespectrum) be converted into corresponding wave-lengths of the water-spectrum by multiplying by $\frac{1}{2}$."

This proposition, which was discovered at first empirically (for a large number of rays) by comparison of the second bydrogen-spectrum with the water-spectrum as far as known at the time, and then theoretically by means of theorem I., recognized as holding good generally, is, according to I., a simple consequence of the fact that the modified hydrogenmolecule $\mathrm{H}^{\prime}$ in $\mathrm{H}_{2} \mathrm{O}$-vapour occupies exactly half the volume it occupies in the free condition. This observation put me in possession of a large number of previously unknown wavelengths of the water-spectrum, of those namely which hydrogen produces under the influence of the oxygen in watervapour, and enabled me to send (on May 9, 1887) to Prof. G. D. Liveing, at Cambridge, a long list of hitherto unknown wavelengths of the water-spectrum for the purpose of experimentally testing the correctness of my mathematico-chemical disturbance-theory; a prediction which, as I am informed by letters of the 19th and 21st of June from Prof. Liveing, has been verified in the most satisfactory manner, as far as the observations have yet been made. The correspondence is shown for the rays from $\lambda=2800$ to $2607 \cdot 8$ and from $\lambda=2603$ to 2449 , in the following Table.

It has not yet been possible to verify the rest of the lines predicted by me on the 9 th of May, from $\lambda=2449$ to $\lambda=2207$, on account of their extreme feebleness. Below 2200 Messrs. Liveing and Dewar have not yet been able to detect any lines of the water-spectrum. Nevertheless, according to my theory, there must exist a still more refrangible section of the waterspectrum of altogether extraordinary feebleness, the wavelengths of which correspond to the wave-lengths of the hydrogen-spectrum given by Dr. B. Hasselberg in his Zusatz zu seinen Untersuchungen über das II. Wasserstoffspektrum, 1884 . 
and the Line-spectra of Hydrogen and Oxygen.

Letter of June 19.

\begin{tabular}{|c|c|c|c|}
\hline Predicted. & Observed. & Predicted. & Observed. \\
\hline $\begin{array}{l}2800 \cdot 5 \\
2798 \cdot 5 \\
2792 \cdot 5 \\
2768 \cdot 5 \\
2759 \\
2753 \\
2749 \\
2742 \\
2731 \cdot 5\end{array}$ & $\begin{array}{r}2799 \cdot 8 \\
2797 \cdot 6 \\
2793 \cdot 8 \\
2768 \cdot 3 \\
2759 \cdot 7 \\
2753 \cdot 1 \\
2748 \cdot 2 \\
2742 \cdot 7 \\
\left\{\begin{array}{l}2732 \cdot 1 \\
2730 \cdot 5\end{array}\right. \\
\left\{\begin{array}{l}2718 \cdot 2 \\
2717 \cdot 2\end{array}\right. \\
2713 \cdot 6 \\
2709 \cdot 5 \\
\left\{\begin{array}{l}2706 \cdot 2 \\
2705 \cdot 2\end{array}\right. \\
\left\{\begin{array}{l}2701 \cdot 5 \\
2699 \cdot 7\end{array}\right. \\
\left\{\begin{array}{l}2693 \cdot 7 \\
2693 \cdot 2\end{array}\right. \\
\left\{\begin{array}{l}2687 \cdot 6 \\
2687 \cdot 2\end{array}\right.\end{array}$ & $\begin{array}{l}2682 \cdot 5 \\
2677 \cdot 5 \\
2672 \\
2667 \cdot 5 \\
2660 \\
2652 \\
2646 \cdot 5 \\
264 \cdot 5 \cdot 5 \\
2637 \cdot 5 \\
2633 \\
2629 \cdot 5 \\
2623 \cdot 5 \\
2615 \cdot 5 \\
2612 \\
2607 \cdot 5\end{array}$ & 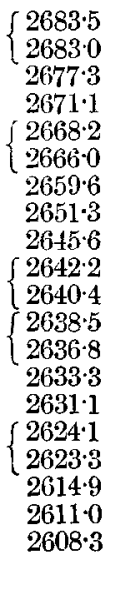 \\
\hline
\end{tabular}

Letter of June 26.

\begin{tabular}{|c|c|c|c|}
\hline Predicted. & Observed. & Predicted. & Observed. \\
\hline $\begin{array}{l}2603 \\
2599 \\
2595 \cdot 5 \\
2591 \\
2585 \\
2578 \cdot 5 \\
2572 \cdot 5 \\
2564 \cdot 5 \\
2556 \\
2542 \\
2535 \\
2532 \cdot 5 \\
2528 \\
2525 \\
2520 \cdot 5\end{array}$ & $\begin{array}{r}2603 \cdot 2 \\
2598 \cdot 6 \\
2596 \cdot 4 \\
2591 \cdot 3 \\
2584 \cdot 4 \\
2578 \cdot 3 \\
2573 \cdot 4 \\
2565 \cdot 4 \\
2556 \cdot 4 \\
2542 \cdot 7 \\
\left\{\begin{array}{l}2536 \cdot 6 \\
2534 \cdot 1\end{array}\right. \\
2531 \cdot 4 \\
2529 \cdot 2 \\
2524 \cdot 2 \\
\left\{\begin{array}{l}2521 \cdot 7 \\
2519 \cdot 8\end{array}\right.\end{array}$ & $\begin{array}{l}2508 \cdot 5 \\
2491 \\
2487 \cdot 5 \\
2484 \\
2479 \\
2473 \cdot 5 \\
2467 \cdot 5 \\
2464 \cdot 5 \\
2460 \cdot 5 \\
2454 \cdot 5 \\
2449\end{array}$ & 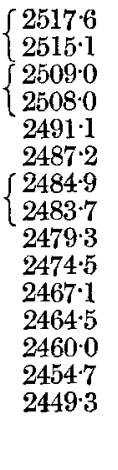 \\
\hline
\end{tabular}

The wave-lengths of the relatively somewhat brighter lines of this section of the water-spectrum are $2248 \cdot 7,2244 \cdot 8$, $2230 \cdot 1,2223 \cdot 5,2205 \cdot 8,2173 \cdot 5,2169 \cdot 4,2111 \cdot 0,2110 \cdot 8$, 
$2105 \cdot 9,2102 \cdot 2,2099 \cdot 6,2097 \cdot 5,2090 \cdot 8,2089 \cdot 7,2088 \cdot 2$, $2087 \cdot 2,2085 \cdot 3,2078 \cdot 0,2038 \cdot 7,2034 \cdot 6,2033 \cdot 2,2031 \cdot 0$.

The experimental verification of this prediction can only succeed with an altogether special arrangement of apparatus. Possibly the nse of soveral sparks or flames, one behind the other, striking through moist gas (or a broad stream of watervapour $)^{*}$, and the observation of the rays emitted in the direction of the line joining them, might succeed, since the rays emitted by the more distant sparks (or flames) would strengthen the vibrations which were produced by those nearer the observing-telescope. It might also be advisable, in accordance with a suggestion of my colleague, Prof. Zenger, to bathe the photographic plates in a solution of chlorophyll as concentrated as possible, and then to dry them.

(2) "The wave-lengths of the elementary line-spectrum of hydrogen may be divided into two groups, $(a)$ and $(b)$; so that the wave-lengths of the one group $(a)$ are transformed into corresponding wave-lengths of the water-spectrum by multiplication by the constant 0.6336 (very nearly $\frac{1}{3} 9$ ), and those of the other group $(b)$ by multiplication of the con$\operatorname{stant} \frac{4}{5} . "$

From this it follows, by means of theorem I., that hydrogen consists of two primary elements, $a$ and $b$; of which the one, $a$, produces the group $(a)$ under the influence of $b$; the second, $b$, produces the group (b) under the influence of $a$. If $[a]$ and $[b]$ are relatively the volumes which the substances $a$ and $b$ occupy in a unit-volume of hydrogen, then

$$
[a]+[b]=1,
$$

and, further,

$$
\frac{1}{3} 9[a]+\frac{4}{5}[b]=\frac{2}{3},
$$

whence

$$
[a]:[b]=4: 1, \quad[a]=\frac{4}{5}, \quad[b]=\frac{1}{5} \text {. }
$$

Hence hydrogen is a compound of one volume of the primary substance $b$, with four volumes of the other primary substance $a: H=b a_{4}$. It is thus a compound analogous to ammonium, $\mathrm{NH}_{4}$, of which the volume will increase in the ratio $2: 3$ upon dissociation at a sufficiently high temperature.

The substance $a$ is the lightest of all gaseous substancesmuch lighter than hydrogen; and the substance $b$ is, if we assume $a$ to be a monovalent element, also a gaseous element and pentavalent similar to nitrogen. The line-spectra of the

* Or better, of several such hydrogen flames in oxygen gas. 
primary substances $a$ and $b$ may now easily be calculated by means of (I.) from the corresponding gronps $(a)$ and $(b)$ by multiplication with the factor $\frac{3}{2}$, in which operation, unfortanately, the errors of the wave-lengths increase in the same proportion. The star-spectra described by Mr. Huggins in the Philosophical Transactions (1880) vol. clxxi. partii.pp.669690 , those namely of $\alpha$ Aquilæ and Arcturus, of which the most refrangible rays are hydrogen-rays, and by comparison with the water-spectrum in accordance with (2) and with the solar spectrum may be confirmed as hydrogen-lines and corrected, enable us to fully complete the hydrogen-spectrum as far as known in the ultra-violet portion, and to construct a very complete spectrum of the primary element $b$. I give here the spectra which I have calculated for the elements $(a)$ and $(b)$ of hydrogen, comparing them with the corresponding Fraunhofer- and chromosphere-lines.

The wave-lengths of the Fraunhofer-lines were taken at once from a good copy of Angström's Atlas, and those of the chromospheric lines from Young's second list. I propose to go over the calculations and comparisons as soon as I have at my disposal Thollon's Nouveau Dessin du Spectre Solaire, Piazzi Smyth's 'The Visual Solar Spectrum in 1884,' and especially A. Rowland's 'Photographic Map of the Solar Spectrum.'

\begin{tabular}{c|c}
$\begin{array}{c}\text { Spectrum of } \\
\text { element } a .\end{array}$ & $\begin{array}{c}\text { Solar spectrum } \\
\text { of Ångström. }\end{array}$ \\
$\lambda=9842 \cdot 4$ & \\
$7290 \cdot 2^{*}$ & 7290 \\
$6510 \cdot 2$ & 6511 \\
$6150 \cdot 6$ & $6150 \cdot 5$ \\
5653.5 \&c. & $5653 \cdot 3$
\end{tabular}

(With possible errors amounting to a unit of Angström's scale. The first two wave-lengths are much more exact than the following ones, because they are derived from the wavelengths of $\mathrm{H}_{\alpha}$ and $\mathrm{H}_{\beta}$, as measured with the greatest care by Mendenhall.)

* Coincides nearly with a telluric line 7290.3 (Fievez). 
Prof. A. Grünwald on the Spectrum of Water-vapour

\begin{tabular}{|c|c|c|c|}
\hline $\begin{array}{l}\text { Spectrum of } \\
\text { element } b \text {. }\end{array}$ & $\begin{array}{l}\text { Solar spectrum, } \\
\text { according to } \\
\text { Angström. }\end{array}$ & $\begin{array}{l}\text { Spectrum of } \\
\text { element } b \text {. }\end{array}$ & $\begin{array}{l}\text { Solar spectrum, } \\
\text { according to } \\
\text { Angström. }\end{array}$ \\
\hline \begin{tabular}{c|}
5954 \\
$5951 \cdot 8$ \\
5943 \\
5940 \\
$5924 \cdot 4$ \\
5916 \\
5904 \\
$5899 \cdot 3$ \\
5897 \\
$5892 \cdot 1$ \\
5886 \\
$5874 \cdot 5$ \\
\\
$5855 \cdot 4$ \\
5833 \\
Several lines \\
from \\
5808 \\
to \\
5805 \\
Several lines \\
from \\
5793 \\
to \\
$\mathbf{5 7 8 4}$ \\
5775 \\
$5752 \cdot 5$ \\
$5694 \cdot 1$ \\
$5618 \cdot 2$
\end{tabular} & \begin{tabular}{|} 
5953·9 \\
$5951 \cdot 6$ \\
$5943 \cdot 5$ \\
5940 \\
$5923 \cdot 5$ \\
$5915 \cdot 4$ \\
$5904 \cdot 6$ \\
5899 \\
5897 \\
$5892 \cdot 1$ \\
$\left\{\begin{array}{l}5885 \cdot 5 \\
5886 \cdot 5\end{array}\right.$ \\
Chrom. $5874 \cdot 9$ \\
Helium-line. \\
$5855 \cdot 2$ \\
$5832 \cdot 5$ \\
$\left\{\begin{array}{l}5808 \cdot 2 \\
5807 \cdot 2 \\
5805 \cdot 7 \\
5804 \cdot 4 \\
5803 \cdot 5\end{array}\right.$ \\
$\left\{\begin{array}{l}5793 \\
5792 \cdot 4 \\
5790 \cdot 3 \\
5786 \cdot 8 \\
5784 \cdot 5 \\
5783 \cdot 0\end{array}\right.$ \\
$\left\{\begin{array}{l}5774 \\
5752 \cdot 2 \\
5751 \cdot 8\end{array}\right.$ \\
5694 \\
$5618 \cdot 0$
\end{tabular} & $\begin{array}{l}5593 \cdot 3 \\
5577 \cdot 3 \\
5560 \cdot 1 \\
5535 \cdot 6 \\
5524 \cdot 3 \\
5515 \cdot 9 \\
5511 \\
5494 \cdot 1 \\
5485 \cdot 5 \\
5482 \cdot 3 \\
5479 \cdot 5 \\
5455 \cdot 1\end{array}$ & $\begin{array}{c}5593 \\
5577 \cdot 5 \\
5559 \cdot 6 \\
5536 \cdot 2 \\
5524 \cdot 8 \\
5515 \cdot 5 \\
5511 \cdot 2 \\
5493 \cdot 8 \\
5485 \cdot 6 \\
5482 \cdot 5 \\
5479 \cdot 9 \\
5454 \cdot 8 \\
\text { Chrom. } 5454 \cdot 7 \\
\text { Chrom. } 5417 \cdot 9 \\
\text { Chrom. } 5412 \cdot 4 \\
\text { Chrom. } 5403 \cdot 1 \\
\{5403 \cdot 0 \text { to } \\
5403 \cdot 3 \\
5389 \cdot 6 \\
5376 \cdot 5 \\
5364 \cdot 0 \text { Fre. } \\
\text { 5364.2 } \\
\text { Chrom. } 5340 \cdot 2 \text { Fe.? } \\
\text { Mn.? } \\
5327 \cdot 0 \text { Fe. } \\
5274 \cdot 7 \\
5259 \cdot 6 \\
\text { Chrom. } 5199 \cdot 7 \\
\text { Chrom. } 5187 \cdot 3 \\
\text { Probably titanium. } \\
\text { \&c. }\end{array}$ \\
\hline
\end{tabular}

Although the fundamental law I. was originally obtained only for compounds of primary elements, it is important to observe that it holds very nearly for compounds of compound radicals, so far as these really behave as "atoms." A proof of this, which is at the same time interesting and an important confirmation of my theorem, is the fact that the wave-lengths of all the hydrogen and oxygen rays, if multiplied by 2 (the mean condensation-factor of $\mathrm{H}$ and $\mathrm{O}$ upon their combination to $\mathrm{H}_{2} \mathrm{O}$ ), are converted into the wave-lengths of corresponding $\mathrm{H}_{2} \mathrm{O}$ rays, at least so far as the $\mathrm{H}_{2} \mathrm{O}$ spectrum is known, and can be compared with them.

(3) In the search for the reduction-factor of the primary constituent $a$ of hydrogen to the $\mathrm{H}_{2} \mathrm{O}$ spectrum several remarkable relationships were obtained. It appeared that the ray 4158 , into which the chief ray $\mathrm{H}_{\alpha} 6562$ of $\mathrm{H}$ is converted by multiplication with $0 \cdot 6336$, is an hitherto unknown (as such) ray of the water-spectrum, and that by means of the factor $\frac{20}{27}$ 
it yields another strong ray $(\lambda=3080)$ of the $\mathrm{H}_{2} \mathrm{O}$-spectrum. The ray 4158 occurs, namely, amongst a group (3986, 4005, to 4645 ) of rays which $\mathrm{H}$. W. Vogel has observed in the spectrum of rarefied hydrogen (whether obtained electrolytically or from potassium formiate), the derivation of which from hydrogen was, however, very doubtful. In view of the fact that in these methods of preparation of hydrogen it is difficult to avoid the presence of traces of water-vapour, it was a probable assumption that at least some of the doubtful rays, and amongst them in particular the ray 4158 , might arise from the traces of water-vapour contained in this hydrogen, and might be rays in themselves very weak in presence of hydrogen, but which, being reinforced by harmonic vibrations of the latter, become visible. If this surmise were correct, it might be expected that the wave-lengths of those of Vogel's rays which belong to the same group of $\mathrm{H}_{2} \mathrm{O}$ rays as 4158 might also be reduced to the $\mathrm{H}_{2} \mathrm{O}$-spectrum by multiplication with the factor $2 \frac{2}{2}$. The supposition was verified in a remarkable manner, in particular for the rays 3986,4005 , 4047, 4065, 4067, 4078, 4152, 4158, 4168, 4193, 4201, \&c., so that these belong to the $\mathrm{H}_{2} \mathrm{O}$-spectrum; and by division by 0.6336 are converted into very feeble rays of hydrogen, hitherto unknown, with the exception of $\mathrm{H}_{\alpha}$, which on account of their extreme feebleness have escaped observation. Their approximate wave-lengths are placed together with the nearest lines of the solar spectrum, as given by Angström.

\begin{tabular}{c|c} 
HI-rays. & $\begin{array}{c}\text { Solar spectrum } \\
\text { (Angström). }\end{array}$ \\
6291 & $6291 \cdot 4$ \\
6321 & $6321 \cdot 5$ \\
$6387 \cdot 3$ & $?$ \\
$6415 \cdot 7$ & $6415 \cdot 6$ \\
& (Chromosphere, \\
$6418 \cdot 9$ & Young). \\
$6436 \cdot 2$ & $6418 \cdot 7$ \\
$6553 \cdot 0$ & $(6438 ?$ Ca) \\
$\mathrm{H}_{\alpha} 6562$ & $?$ \\
$6578 \cdot 3$ & 6562 \\
& $6576 \cdot 9 ?$ \\
$6617 \cdot 7$ & (Chromosphere, \\
$6630 \cdot 3$ & Young). \\
& $?$ \\
\end{tabular}

With a possible error of 1.6 of Ångström's unit. Phil. Mag. S. 5. Vol. 24. No. 149. Oct. 1887. 
A careful comparison of the spectra of hydrogen intentionally mixed with various very small quantities of $\mathrm{H}_{2} \mathrm{O}$ vapour is much to be desired, and ought to produce the experimental confirmation of the origin of the rays 3986, $4005,4007, \ldots 4201$, \&c. The ray 4158 lies very near to a very weak ray, 4158.7 , of the second so-called compound spectrum of hydrogen observed by Dr. B. Hasselberg, it indeed the latter be not identical with it, having its origin in the presence of a trace of aqueous vapour. The same ray was moreover observed in air and in oxygen, in the mode adopted by Plücker.

(4) $\alpha$. "The wave-lengths of the elementary line-spectrum of oxygen may be divided into two groups, $\left(\mathrm{H}^{\prime}\right)$ and $\left(\mathrm{O}^{\prime}\right)$, of which the first consists of certain rays of the second compound $\mathrm{H}$-spectrum, which are converted into the corresponding rays of the water-spectrum by multiplication with $\frac{1}{2}$."

$\beta$. "The groups $\left(0^{\prime}\right)$ may be divided into two groups, $\left(b^{\prime}\right)$ and $\left(\mathrm{O}^{\prime \prime}\right)$; so that the one $\left(b^{\prime}\right)$ by multiplication by $\frac{23}{32}$ passes into a group of the corresponding wave-lengths of the $\mathrm{H}_{2} \mathrm{O}$ spectrum, but by multiplication by $\frac{41}{46}$ into a group of homologous wave-lengths of the primary substance $b$ chemically combined in $\mathrm{H}$, whilst the other group $\left(\mathrm{O}^{\prime \prime}\right)$ may be converted into a corresponding group of the $\mathrm{H}_{2} \mathrm{O}$-spectrum by multiplying it by $\frac{5}{8}$."

$\gamma$. Finally, the last group $\left(\mathrm{O}^{\prime \prime}\right)$ may again be resolved into two groups $\left(b^{\prime \prime}\right)$ and $(c)$ of wave-lengths. The first of these $\left(b^{\prime \prime}\right)$ multiplied by $\frac{21}{2}$ gives a group of the $\mathrm{H}_{2} \mathrm{O}$-spectrum, and multiplied by $\frac{59}{70}$ is reduced to a corresponding group of the $\mathrm{H}$-spectrum which belongs to the primary substance $b$ in $\mathrm{H}$.

The second group (c) by multiplication by $\frac{3}{5}$ is transformed into a homologous group of $\mathrm{H}_{2} \mathrm{O}$-rays."

From these most important and remarkable relationships and characteristic data, which are not derived from single rays, but by the comparison of whole series of numerous rays of oxygen, $\mathrm{H}_{2} \mathrm{O}$-vapour, and hydrogen, we obtain by means of the fundamental theorem I. easily, and at once, the chemical structure of oxygen in the interval of temperature in which it radiates the elementary line-spectrum. If in fact $\mathrm{H}^{\prime}, \mathrm{O}^{\prime}$, $b^{\prime}, \mathrm{O}^{\prime \prime}, b^{\prime \prime}, c$ be the substances which, in their combined condition within the oxygen, emit the above similarly-denoted groups of rays, $(\mathrm{H})^{\prime},\left(\mathrm{O}^{\prime}\right),\left(b^{\prime}\right),\left(\mathrm{O}^{\prime \prime}\right),\left(b^{\prime \prime}\right)$, and $(c)$, and $\left[\mathrm{H}^{\prime}\right],\left[\mathrm{O}^{\prime}\right],\left[b^{\prime}\right],\left[\mathrm{O}^{\prime \prime}\right],\left[b^{\prime \prime}\right]$, and $[c]$ be the volumes which they occupy in a unit-volume of oxygen, we have the equations

$$
\begin{aligned}
& {\left[\mathrm{H}^{\prime}\right]=\frac{1}{2}, \quad\left[\mathrm{O}^{\prime}\right]=\frac{1}{2},} \\
& {\left[b^{\prime}\right]+\left[\mathrm{O}^{\prime \prime}\right]=\left[\mathrm{O}^{\prime}\right]=\frac{1}{2} ;}
\end{aligned}
$$


and in accordance with theorem I., in view of the facts stated under (4) $\beta$,

whence

$$
\frac{23}{32}\left[b^{\prime}\right]+\frac{5}{8}\left[0^{\prime \prime}\right]=\frac{2}{3}\left[O^{\prime}\right]=\frac{1}{3},
$$

and

$$
{ }^{*}\left[b^{\prime}\right]:\left[\mathrm{O}^{\prime \prime}\right]=4: 5,
$$

$$
\left[b^{\prime}\right]=\frac{4}{9}\left[O^{\prime}\right]=\frac{2}{9}, \quad\left[O^{\prime \prime}\right]=\frac{5}{9}\left[O^{\prime}\right]=\frac{5}{18} .
$$

But, further,

$$
\frac{5}{8}\left[\mathrm{O}^{\prime \prime}\right]=\frac{5}{8} \times \frac{5}{18}=\frac{25}{144}
$$

is the space which $\mathrm{O}^{\prime \prime}$ occupies within the oxygen in $\mathrm{H}_{2} \mathrm{O}$ vapour; then

$$
\left[b^{\prime \prime}\right]+[c]=\left[\mathrm{O}^{\prime \prime}\right]=\frac{5}{18} ;
$$

and according to theorem I., taken with the facts of $4(\gamma)$, we have

whence, again,

$$
\left.\frac{21}{3} 1 b^{\prime \prime}\right]+\frac{3}{5}[c]=5\left[\mathrm{O}^{\prime \prime}\right]=\frac{25}{144}
$$

and

$$
* *\left[b^{\prime \prime}\right]:[c]=4: 5,
$$

$$
\begin{aligned}
& {\left[b^{\prime \prime}\right]=\frac{4}{9}\left[0^{\prime \prime}\right]=\frac{4}{9} \times \frac{5}{18}=\frac{10}{81},} \\
& {[c]=\frac{5}{9}\left[0^{\prime \prime}\right]=\frac{25}{162} .}
\end{aligned}
$$

The chemical structure of oxygen in the above-named interval of temperature is therefore expressed by the chemical volume-formula

$$
\begin{aligned}
& \mathrm{O}=\mathrm{H}^{\prime} \cdot \mathrm{O}^{\prime}, \quad \mathrm{O}^{\prime}=b_{4} \cdot \mathrm{O}^{\prime \prime}{ }_{5}, \quad \mathrm{O}^{\prime \prime}=b_{4} c_{5} . \\
& \mathrm{O}=\mathrm{H}^{\prime} \cdot\left[b_{4} \mathrm{O}^{\prime \prime}{ }_{5}\right]=\mathrm{H}^{\prime} \cdot\left[b_{4} \cdot\left(b_{4} c_{5}\right)_{5}\right] .
\end{aligned}
$$

That is to say, "Oxygen in its simplest molecular condition is a compound of the modified hydrogen $\mathrm{H}^{\prime}$, which radiates the second so-called compound line-spectrum of hydrogen, with a substance $O^{\prime}$ in equal volumes without condensation. The latter $\mathrm{O}^{\prime}$ is a compound of four volumes of the pentavalent (nitrogen-like) element $b$ of hydrogen in a special condition of chemical condensation with five volumes of a substance $\mathrm{O}^{\prime \prime}$, which itself again consists of four volumes of the primary element $b$ (in one of the former various chemical conditions) with five volumes of a new hitherto unknown primary substance."

As I have here deduced the chemical structure of $\mathrm{H}$ and $\mathrm{O}$ by a mathematico-spectroscopic method, so I should no doubt be able to determine the chemical structure of the so-called elements nitrogen and carbon by means of my chemical theory of disturbance, if I were furnished by skilful spectroscopists with complete and trustworthy lists of the wave-lengths of 2 B 2 


\section{Prof. A. Grünwald on the Spectrum of Water-vapour}

ammonia, $\mathrm{NH}_{3}$, and of methane, $\mathrm{CH}_{4}$, at the low temperature of electric discharge (to avoid dissociation) or the absorptionspectra of these gases. These spectra must extend in the ultra-violet portion as far as wave-lengths $1728 \times 10^{-7}$ millim. and $1383 \times 10^{-7}$ millim., and, if possible, still further.

Hitherto, so far as nitrogen is concerned, I have only succeeded in showing that it is in its simplest chemical condition (like oxygen) a compound of the modified hydrogen $\mathrm{H}^{\prime}$ with a substance $\mathrm{N}^{\prime}$ in equal volumes without condensation; and that the latter substance $\mathrm{N}^{\prime}$ must have an entire large group of atoms in common with oxygen, inasmuch as a group of more than forty N-rays (i.e. their wave-lengths) may be transformed by multiplication by the factor $\frac{47}{46}$ into a corresponding group of $\mathrm{O}$-rays $(i . e$. their wave-lengths).

The volume-formula of nitrogen has most probably the same form as that of oxygen, only written with smaller indices because the atomic weight of nitrogen (14) is less by 2 than the atomic weight of oxygen.

In carbon also I was able, by simple comparison of the spectrum with those of $\mathrm{H}_{2} \mathrm{O}$-vapour, of $\mathrm{H}$, and of $\mathrm{O}$, to establish the existence of the primary substance $b$ in at least two different chemical conditions, as well as the occurrence of the primary substance $c$, which is also contained in oxygen.

(5) $a$. In the experiments which I made to determine the factor of reduction $\left(0.6336\right.$, very nearly $\left.\frac{19}{30}\right)$ for the substance $a$ in $\mathrm{H}$ to the $\mathrm{H}_{2} \mathrm{O}$-spectrum, I found that this factor is the mean or chief reduction-factor of the four atoms which in $\mathrm{H}$ are combined with the substance $b$; but that further special reduction-factors to the $\mathrm{H}_{2} \mathrm{O}$-spectrum belong to the separate atoms of these four, of which I succeeded in determining two, viz. $\frac{3}{4}$ and $\frac{56}{75}$, and in verifying them, at least so far as they could be compared with the known $\mathrm{H}_{2} \mathrm{O}$-spectrum.

If then $\lambda$ be the wave-length of an H-ray of the elementary line-spectrum which is due to the substance $a$ in $H$, then $0.6336 \lambda$ (empirically, theoretically more nearly 190 ), $\frac{3}{4} \lambda$, and $\frac{56}{75} \lambda$ are with considerable accuracy three different wavelengths of the $\mathrm{H}_{2} \mathrm{O}$-spectrum, if the latter is known with sufficient exactness.

$\beta$. If, on the other hand, $\lambda$ be the wave-length of an H-ray which is produced by the substance $b$ combined in $\mathrm{H}$ with the element $a$, then not only must $\frac{4}{5} \lambda$ be a wave-length of the $\mathrm{H}_{2} \mathrm{O}$-spectrum according to (2), but also according to (4) $\beta$ (or (4) $\gamma$, as the case may be) $\frac{46}{41} \lambda$ and $\frac{70}{59} \lambda$ must be two wavelengths of the 0 -spectrum; further, $2_{32}^{3} \times \frac{46}{41} \lambda$ and $\frac{21}{32} \times \frac{70}{59} \lambda$ must be two wave-lengths of the $\mathrm{H}_{2} \mathrm{O}$-spectrum, and recog- 
nizable as such, provided that the elementary $\mathrm{O}$-spectrum is known sufficiently exactly, which is unfortunately not the case with very faint rays.

We are thus in possession of mathematico-spectroscopic criteria for the hydrogen-rays, which possess an unmistakable resemblance to the chemical reactions for the detection and recognition of substances.

\section{III.}

The Dissociation of Hydrogen in the Sun's Atmosphere.

A careful comparison of the lines of the above-described spectrum of the primary element $b$ with the corresponding Fraunhofer and chromospheric lines, as given above, shows that the element $b$ must occur in the free state in the sun's atmosphere, and must be identical with helium, of which hitherto only one ray, $\mathrm{D}_{3} 5874.9$, is known. Hence, as well as by the close agreement of the lines of the $a$-spectrum, also given above, with corresponding lines of the solar spectrum, it is proved that hydrogen occurs in the sun's atmosphere in a dissociated condition.

But if this is the case the constituent $a$ must not only be present wherever the dissociation takes place, together with the helium $b$, but as the lightest of all gases it must exist above those regions of the photosphere which can only be reached by the much heavier helium and the other elements exceptionally in powerful eruptions.

But if this occurs, and if in these very high and relatively cool regions the helium $b$ and the primary substance $a$ meet, then, under the extremely small pressure existing there, all the conditions are present for the formation of the modified ammonium-like hydrogen, which radiates the second compound hydrogen-spectrum. Such regions, which correspond to the extreme portion of the corona, will therefore specially exhibit the lines of the second hydrogen-spectrum together with those of ordinary hydrogen.

The hitherto unknown corona-substance appears to be a gas with the properties indicated above, which emits the so-far solitary known ray at 1474 of Kirchhoff's scale, or $\lambda=5315 \cdot 9$ (about) of Angström's scale, and which I may perhaps be allowed to call "Coronium." It is easy, then, to assume that the primary constituent $a$ of hydrogen is identical with this coronium, which, in any case, must be a different substance from helium, since the corona-line $5315 \cdot 9$ often remains unaltered, whilst at the same time the helium-line $\mathrm{D}_{3}$ is either broadened, or distorted and displaced, $i$. e. exhibits 


\section{Dissociation of Hydrogen in the Sun's Atmosphere.}

the changes in form observed by Lockyer. If this assumption is correct, $\lambda=5315.9$ (about) must be a wave-length of the above a-spectrum, which does not occur amongst the numbers found by calculation only because the wave-lengths corresponding to the element $a$ in hydrogen are not completely known. In this case $\lambda=5315^{\circ} 9 \times \frac{2}{3}$ must be a wavelength of the elementary $\mathrm{H}$-spectrum. It is true that the wave-length (about) $\frac{2}{3} \times 5315 \cdot 9=3544.0$ (about) does not occur in the list of wave-lengths at present known as belonging to hydrogen; but if we take the extremely rich section of the $\mathrm{H}_{2} \mathrm{O}$-spectrum corresponding to the second hydrogen-spectrum as given by Dr. Hasselberg (see II. (1)) for the comparison, it satisfies in a very complete manner the criteria given (II. (5) $\alpha$ ) for hydrogen-rays which belong to the substance $a$ within the hydrogen, since $\frac{1}{3} \cdot 9 \times 3544 \cdot 0=2244 \cdot 5, \quad \frac{3}{4} \times 3544 \cdot 0=2658^{\circ} 0$, and $\frac{56}{75} \times 3544.0=2646.1$ differ only by a few tenths of an Angström unit $\left(10^{-7}\right.$ millim.) from the corresponding wavelengths of the $\mathrm{H}_{2} \mathrm{O}$-spectrum: $2244 \cdot 8,2658 \cdot 6$, and 2645.4 . The ray at about $\lambda=3544 \cdot 0$ is, therefore, an hitherto unknown ray of hydrogen, the existence of which will probably be shown experimentally; $\lambda=5315.9$ is a wave-length of the primary element $a$ (previously overlooked in this calculation for want of sufficient data), which is, therefore, probably identical with coronium. I must not omit to remark that the line $5317 \cdot 28$ of the second hydrogen-spectrum described by Dr. B. Hasselberg in 1883 lies very near to the corona-line 5315.9 ; and from what has been said above might possibly be observed, together with other lines of the latter spectrum, in the comparatively cooler regions of the corona far removed from the photosphere. If these two lines are really different, it must be possible, under favourable circumstances, to observe both lines at the same time in the corona- 5315.9 in the hot portion nearer the photosphere, and the other in the less hot regions further from the photosphere, for which observation a favourable opportunity offers in the total solar eclipse of the 18th August.

The like holds good of the known chromosphere-line $\lambda=4471 \cdot 2$ of Rayet (Lorenzoni's $f$ ), which differs by only 0.3 from the nearest line of that part of the second hydrogenspectrum which Dr. B. Hasselberg has described in 1884 (Zusatz zu meinen Untersuchungen), viz. the line $\lambda=4470 \cdot 9$; so also with the chromosphere-line 4712.5 , which, like the former line $4471 \cdot 2$, is rather a band than a line, and like this is ascribed to Ce, but differs from the nearest line of the second $\mathrm{H}$-spectrum only by $0 \cdot 6$.

The line 4471:2, which I was disposed to take for a belium- 
line, does not belong to helium, because it does not satisfy all the mathematico-spectroscopic criteria of helium-lines. This is also confirmed by the observations made by Prof. Young on August 3 and 5, 1872, in which, at the same time that $\mathrm{D}_{3}, 5015 \cdot 0,4571 \cdot 4$, \&c., were very strongly disturbed, the lines $4471 \cdot 2,7055$, and the corona-line $5315^{\circ} \cdot 9$ remained unaltered. I wish particularly to observe, with reference to the forthcoming solar eclipse, that my calculations and comparisons show that the lines Fievez's 4612.5, 4564.5, Young's 5570, 5450, Tacchini's 4943, 5031, and (what is very important) two lines very near to the magnesium-lines $b_{1}$ and $b_{2}$, belong to helium; the line 7055 (?) very probably to coronium; lastly, the lines observed May 17, 1882, by Capt. Abney and Dr. Schuster in Egypt (4501, 4473, 4401, $4224,4212,4195,4179,4085$, and 4067$)$, as well as at least one of the four red corona-lines $(6489,6492,6494,6498)$, seen simultaneously by Tacchini, viz. 6492 (if not all four), belong to the second compound spectrum of hydrogen.

The lines seen in the corona by the last-named spectroscopists and astronomers ought, therefore, in accordance with what has been said above, to originate in the comparatively cooler portions of the corona far removed from the photosphere, in which the elements of hydrogen separated in the hotter regions partly unite to form the common hydrogen, partly to form the ammonium-like hydrogen which produces the second hydrogen-spectrum.

P.S. Whilst passing through the press, a new and remarkable confirmation of the wave-lengths of the water-spectrum predicted by me on May 9, 1887, has reached me from Prof. G. D. Liveing, viz. $\lambda=2331 \cdot 1$ to $\lambda=2437 \cdot 2$.

Prague, July 17, 1887.

XLVII. Notices respecting New Books.

Coal-Tar and Ammonia. Being the Second and enlarged Edition of - A Treatise on the Distillation of Coal-Tar and Ammoniacal Liquor:' By GHORGe LUNae, Ph.D., Professor of Technical Chemistry in the Federal Polytechnic School, Zurich. London: Gurney and Jackson, 1 Paternoster Row (Successors to Mr. Van Voorst). 1887.

$\mathrm{W}^{\mathrm{E}}$ had occasion to speak favourably of the first edition of this work when it appeared in 1882. At that time it consisted of 383 pages and 88 diagrams; it now forms a bandsome wellprinted volume of no less than 739 pages of letterpress and 191 diagrams. 